\title{
PINA BAUSCH: toda imagem é uma narrativa, todo gesto tem uma história
}

\author{
Solange Caldeira *
}

\author{
"But I had only my eyes with which to speak." \\ (William Carlos Williams)
}

\begin{abstract}
A viagem
A viagem é um antigo topos como figuração recorrente para o processo de escrita poética. A recorrência e a longevidade de tal topos não assegura, no entanto, a quem dele se acerca, maior qualidade. Aliás, a repetição pura e simples de alguma imagem clássica parece hoje sugerir uma leitura convencional do texto em questão. Não é o que acontece, porém, em $\mathrm{O}$ Lamento da Imperatriz ${ }^{1}$, cujo eixo, é a figuração de uma escrita labiríntica, viagem pela cidade de Wuppertal de um ponto a outro, numa espécie de análise poético-reflexiva das imagens da cidade e da representação do poeta como viajante e sujeito daquele lugar.

É com certo ceticismo que se parece fixar a viagem como motivo e objeto de reflexão, como se só fosse este o tema, na verdade Bausch desconstrói qualquer aura aventuresca ou ilusão ilustrada em torno da idéia de andar pelos lugares. Afirma, porém o ir e o regressar/ sobre as mesmas pegadas, o caminhar para o lugar-nenhum a que parecem conduzir os passos, num falso movimento do corpo pelo mundo.

Às vezes são movimentos literalmente em falso, transformados em poesia corporal, como a moça vestida como bunny girl do clube Playboy, que tropeça em seus próprios pés, ou a dança da mulher encharcada, em cima de uma ponte que balança, no meio de uma tempestade de neve, em que ela perde subitamente o equilíbrio.

Como explica Wim Wenders em Le Souffle de l'Ange:'

"A viagem como sonho de aprendizado, para compreender o mundo,
não é mais possível para nosso tempo. O filme que se poderia fazer seria
a viagem de alguém que tem esta esperança de compreender o mundo e
com quem se passa o contrário: ele vai se dar conta de que seu movimento
o leva ao nada, que, no fim, ele não se moveu um centímetro. Daí o
título: Falso movimento."
\end{abstract}

Esta explicação aplica-se perfeitamente aos labirintos de O Lamento da Imperatriz.

$\mathrm{O}$ antigo topos funciona no sentido de estabelecer uma relação analógica, uma imagem que reforça a ligação, a coesão entre as cenas e com a qual Bausch trabalha em todo o filme.

\footnotetext{
* Professora adjunta da Universidade Federal de Viçosa (UFV), coordenadora das disciplinas de Balé Clássico e Atuação Teatral, do Curso de Dança, Departamento de Artes e Humanidades (DAH). Bailarina, atriz, coreógrafa e pesquisadora na área de dança e teatro. Doutora em Teatro (UNIRIO).
} 
Daí a referência a situações míticas através de figuras que habitam o filme de passagem: o anjo, os corpos caídos na neve, o apelo solitário pela mãe.

Estabelecida essa relação inicial, assiste-se, à medida que se sucedem as cenas, a contínuos ajustes, reajustes e retomadas do motivo inicial: os tiros, a mulher em atitude lutante, o grito pela mãe, a busca de amparo, de carinho, o andar em direção a algum lugar mítico onde se estaria em paz. É isso que parece mover esses corpos. Porque se a regra é a idéia de falso movimento, há um outro, um movimento reflexivo, que de fato marca as cenas e a organização precisa, cuidada. Assim, se a máscara que define o sujeito lírico é a do viajante que vai e volta sobre as mesmas pegadas, sua perspectiva é a do descolamento, a de quem se interroga sobre a própria figuração. E diverte-se em torná-la crescentemente prosaica, passando a todo o momento do ambiente externo para o interno.

A construção poética, apoiando-se num topos clássico, propõe na verdade, imagens desse percurso pelo corpo de Wuppertal, formas de viagem intertextuais. Imagens características de diversas possibilidades expressivas, organizadas pelo ritmo, por repetições quase anagramáticas e duplicações constantes de ações físicas. E, sobretudo, de uma tensão, especialmente significativa, entre o uso freqüente de continuidades do espaço físico externo da cidade de Wuppertal, continuidades que lembram, sem maiores disfarces, o movimento da viagem ou desse caminhar labiríntico das personagens, num texto que vai se estruturando cena a cena, através de associações rápidas, cortes inesperados e analogias, onde os corpos são sintagmas que estabelecem uma singular teia narrativa.

A opção de Bausch pela forma não convencional da dança vem acompanhada de certa tensão interna, que leva a um descolamento reflexivo inevitável. Como no caso da preocupação com a técnica balética, na cena do rapaz com o professor de balé, que está presente, mas devidamente acompanhada por um sinal de ceticismo: a execução apenas mecânica do passo, a preocupação única com a forma, sem conteúdo. Essa é uma crítica ferina ao uso que se faz da forma fixa da dança clássica ou ballet.

Mas há também um vice-versa, na inesperada cena em que o mesmo rapaz da aula de balé dança tranqüilamente com o homem ruivo. Quebra nada gratuita, que cumpre uma função toda especial: a de aproximar figuras até então singulares, isoladas: como a do sujeito lírico, o homem ruivo, sempre em atitude de repouso e complacência, com a do rapaz moreno, até então vítima do rigoroso regime disciplinar tanto do professor de balé, quanto da professora de alemão. Aproximação que se pode traduzir explicitamente como corpo que é matéria, mas que também pode, sabe e deseja. Numa cadeia sensorial em que ações e desejos contaminam-se mutuamente está a bela sugestão de um sujeito-em-metamorfose, que incorpora o movimento, a viagem (ou superposição) de uma máscara a outra, apontando possibilidades de trânsito onde, até então, só se percebia margem, limites.

Outra questão, também ligada a trânsito e limites, é o caminho impreciso. Examine-se o que acontece especificamente nas cenas da mulher "coelhinha" e as cenas em que outras personagens correm, chamando pela mãe. Há uma certa ambiência comum, todas as cenas são externas, nos arrabaldes de Wuppertal, além da dominância do espaço indireto. Há, ainda, certos trechos do filme em que Bausch retoma os mesmos lugares, mas em meio a um esperto jogo de diferenças estabelecido pela estação do ano. Por exemplo, o lugar em que 
anda a "coelhinha" no início do filme é o mesmo em que passeia a mulher do acordeão no final. Só que nesta última cena o chão está coberto de neve. $O$ mesmo se repete nas tomadas do bosque, no início, aparentemente no outono, depois no inverno e na primavera. Também é possível esta observação nas cenas iniciais da mulher-menina de azul, que corre chamando a mãe, na cena de uma mulher sentada só, no meio do bosque coberto de neve e na do homem de robe que anda no mesmo bosque. O lugar é o mesmo, some e reaparece de repente, sugerindo uma redefinição temporal que o liga ao sujeito da ação, num cronotopo que pode ser conector ou seccionante. Porém é nesse mesmo espaço físico que se aproximam, mesmo que seja para logo em seguida patentear diferenças.

Essas retomadas, observando o que há de fundamentalmente diverso é, pois, uma questão de limites, de delimitação espaço-temporal.

É exatamente como tensão constante entre movimento e limite, labirintos, viagens e margens, que se definem a escrita poética e o processo de composição de Pina Bausch em $\mathrm{O}$ Lamento da Imperatriz e outras obras que têm cidades como tema. Graças, sobretudo, a um inteligente uso, desse corpus da cidade, assiste-se, à gênese de uma escrita em processo. E é como questão de limites, de demarcação de campo, que isso se dá. Não é à toa, que no filme, em todo momento, apresente-se essa viagem-movimento, imagem do narrador não só como viajante dos cômodos internos de um edifício, de uma casa, mas também de todo esse espaçotempo externo e determinante do personagem-cidade.

\section{O sujeito}

Um critério de concisão, preocupação com a economia corporal, mas também um gosto acentuado, é claramente perceptível nas encenações de Bausch. Talvez se possa dizer dessa identidade secreta na poética de Pina Bausch, que não se trata mais, pura e simplesmente, de uma série de imagens, mas de uma idéia fixa, de uma forma particular de definição - pela sombra - do sujeito (anti) lírico. Porque, se uma das marcas registradas do seu trabalho, contra a corrente egolátrico-expressiva dos anos 70, foi o decidido descarte desse retrato da subjetividade, isso não implica descaso pela reflexão sobre o sujeito. Justo o oposto. "Expulse a subjetividade, ela retorna a galope" ${ }^{4}$, disse certa vez Georges Poulet ${ }^{5}$ num texto sobre Roland Barthes. No caso de Pina Bausch, há a rejeição de uma poética cuja chave-mestra é a auto-expressão, em favor da co-autoria com seus atores-bailarinos. Posição que acentua uma proliferação de máscaras possíveis para essa meta-eu de suas encenações, e acelera a perseguição de uma outra figuração - nem puramente metafísica, nem só biográfica - para o sujeito lírico. É esta a direção de O Lamento da Imperatriz, que apresenta como motivo dominante do 'texto' a configuração e forma de problematização poética do sujeito.

É na sua relação com o espaço-tempo que Bausch procura configurar um sujeito poético. De um lado, um tempo cosmológico, tempo do seu silêncio, do seu sono, dos seus passos, tempo irreversível, de outro, o tempo psicológico, que o invade em sensação e desejo imperioso de ser, mesmo sabendo-se puro ensaio de tempo e nada, o tempo reversível. Daí a tentativa em paradoxo de capturar o tempo essencial no seu próprio fluxo corporal ou por meio de um diálogo pessoal, intransferível. 
Interlocutor fugidio, duro, silencioso, o tempo escapa, filosoficamente, à captura, e invade o sujeito, e o impele a figurá-lo. A ele, tempo, que é linha desigual, curva do pensamento e do desejo, tempo que é real.

As encenações de Pina Bausch, desde os anos 70, retomam essa tentativa, à beira da metafísica, de compreensão do sujeito contemporâneo.

Sua obra marca o abandono ao uso sistemático de códigos tradicionais da dança, ao mesmo tempo, que sugere uma virada prosaica no diálogo entre o teatro e a dança. Bausch passa a pensar o sujeito na sua relação com o outro, com o mundo, o acaso urbano, e com um eterno presente que impõe como marcas o movimento, a transformação e a consciência, por parte do eu, da sua finitude, da sua solidão.Questão que marca a redefinição de sujeito como figura ou figurações. Aviso prévio de que a paisagem poética agora se tornou decididamente outra: uma linguagem corporal extremamente econômica, e muito bem trabalhada através de um hábil jogo de ironia.

As figurações mais nítidas do sujeito poético saem de um repertório mítico-ficcional sobre possíveis identidades humanas e/ou míticas. Como as perseguições ou buscas que atravessam o filme, em que sujeito ou objeto da procura apenas são supostos, não aparecem concretamente, apenas é possível suspeitar-se sobre possíveis identidades.

Bausch acrescenta aos suspeitos - já familiares nos seus textos - figuras cuja simples presença, em meio ao bosque sombrio de Wuppertal, ao universo anti-social, cruel, que lhe serve de alicerce poético, parece fadada a inquietar, como, por exemplo, os homens que acompanham as crianças pelo bosque, o homem que cava e esconde algo na colina, o que iça e deixa pendurada uma criança na árvore, além dos corpos imóveis que aparecem no meio da neve.

Dessa forma, vem para o primeiro plano o que ficava no fundo do quadro: a tentativa de definição, via cisão, de uma identidade autocorrosiva, secreta, para um ou mais sujeitos. Duelo particular que se espetaculariza, aos olhos do espectador-leitor, através de referências a figuras mais conhecidas, pertencentes a um imaginário corrente, como: a mãe, a procura de amparo, a busca do amor. Ou entre imagens quase surreais, como a da 'coelhinha' correndo na paisagem árida, a mulher que dança na chuva, ou a que procura se equilibrar nos ombros de Jan Minarik, imagens que têm em comum a dimensão lutante, de busca incansável. Ou, impasse talvez ainda maior, entre a paixão crítica e a idéia fixa da ordem, a ponto de sugerir, em alguns momentos, a impossibilidade de maior identificação com quaisquer figurações por parte do espectador-leitor, mesmo que, involuntariamente, pudesse ele também se comportar por vezes como uma espécie de seguidor de pistas e rastros.

É preciso um outro elemento, aquele que permite ao intelecto penetrar nessa atmosfera saturada de paixão. Bausch não escreveu nenhuma história de detetive, mas o cálculo, o momento construtivo, está em sua obra associado de modo total e completo à crueldade. $\mathrm{O}$ que significa essa apropriação da máscara secreta que propõe a dúvida, a incerteza, mantendo laços estreitos com a "tradição moderna". É necessário tentar perceber o sentido desse movimento de aproximação com o desconhecido, dessa figuração aparentemente bifronte para o sujeito.

O impasse dessa identidade-em-cisão do sujeito narrador retorna durante todo o filme, e 
está presente em toda a obra de Bausch. É tematizada diretamente em pelo menos três ótimos exemplos: as relações perigosas entre os homens e as crianças, entre o rapaz e o professor de balé; o igual do desigual, no casal que dança de vestido brilhante, enfim, na identidade secreta de todos os personagens, na desigualdade do que se apresenta em confronto. É preciso caminhar por vias diversas para se compreender a necessidade de figurações em paradoxo para o sujeito na poética de Pina Bausch. Poética centrada não exatamente numa definição do seu sujeito, que é risível, insólido, infra-herói, que se sucede nas imagens paradoxais, capaz de sugerir em auto-ironia o 'nada' que é o ser humano.

Bausch transforma a câmara num olho que olha-para-dentro e, modificando os limites das cenas, torna possível duvidar da imagem 'real', gêmea e substituí-la por uma interrogação, que penetra fundo no espectador-leitor, que incomoda, que o impele a uma reflexão. Talvez a uma resposta, ou atordoamento frente a si próprio, mas sempre uma figura que em suas várias redefinições, persiste na capacidade de auto-ironia, como exemplo: a cena da troca de animais de um lugar para outro, a dança de salão em uma estranha posição, feita pelo rapaz ruivo e o garoto moreno, a mulher de vermelho apitando furiosamente do alto de um edifício, o homem fazendo a barba no meio-fio, no centro da cidade.

\section{O agente da ação}

Quem fala na obra de Pina Bausch? Chama a atenção sua preferência por indeterminações ou por alguma forma não usual como agente da ação. Não faltam ambigüidades, como a troca do que se pensa ser o sujeito, para um outro eu que, mesmo oculto, tem oponentes, limites, aparência sugerida e até antagonismo resolvido. Este é o caso da figuração da 'mãe'. Surge em terceira pessoa, uma abstração, mas ao mesmo tempo figura concreta, que pode ser qualquer uma das várias personagens femininas que aparecem, ou nenhuma. Mas a atenção que capta esse sintagma, explorado em diversas cenas através do chamado de diferentes vozes, é capaz de construir um campo, diverso deste vivido por esse sujeito-mãe (oculto) inicial, só por sua essência mítica e simbólica.

No caso do filme, o abandono do eu em prol de outro sujeito, quase sempre invisível ou sugerido em algumas cenas, obedece à oposição entre aparência e essência, que estrutura a poética bauschiana, e o movimento em direção ao essencial que parece conduzir e resolvê-la ao final. Só depois de se ver todas as cenas, é possível a reconstrução do percurso, pois aí se pode caminhar por traços e pegadas, recompondo, conforme a sensibilidade do receptor, a viagem metafórica da Imperatriz de Bausch.

Além dos sujeitos cambiantes, há ainda outro ponto a observar. Não é em qualquer cena que esses eus explícitos funcionam como sujeitos. Eles também indicam desconstrução, destruição. Por vezes indicam captura, morte daqueles de quem falam. Como o poema dito pela mulher bêbada, que sugere um dos movimentos mais característicos desse eu lírico que narra em agonia o sujeito-objeto amado, em desmontagem, em fracionamento. Sua descrição detalhada da dor de uma perda, também define o lamento que é cerne do filme e temática da obra bauschiana: Eu disse: eras minha vida. 
Ela disse: meu fim está chegando.

Venha só uma vez e não precisará voltar jamais.

Não me maravilha que alguém possa morrer diante da tenda do amado.

Só me maravilha que se possa querer e manter-se vivendo.

Não é de estranhar, então, que, a certa altura, o sujeito, espécie de sujeito oculto mítico apareça e desapareça logo depois, inconcluso, sempre em processo de montagem e desmontagem. O que sugere duas trilhas da escrita poética: a quebra do "sentido essencial" das coisas, pertencente, necessariamente ao âmbito do inexpresso, e a desmontagem, que se figura como um processo de sucessivas e inevitáveis dissecções. O que explica, do ponto de vista da composição cênica, a importância do fragmento e de certo estilhaçamento na estruturação da encenação. O percurso da 'mulher coelhinha', por exemplo: nas cenas iniciais ela caminha em círculos, perdida, só na última cena em que aparece correndo na estrada, usa o espaço direto. O desespero continua, mas o caminho para seu objetivo parece definido.

Há no percurso poético de Bausch uma espécie de nostalgia do passado, que poderia mesmo ser lida como mote possível do seu processo de criação. Desejo que explica em parte a resistência à figuração explícita do sujeito, sempre meio fora da mira do espectador-leitor.

Mas há um certo grupo de objetos $\neg$ o bosque, a mulher, a figura clamada da mãe, os carneiros, os elementos água, terra e ar, o anjo, os corpos caídos, a imensidão do campo verde, ou coberto de neve, ou coberto de folhas secas, o arco-íris ᄀ que não funcionam apenas como referentes para possíveis descrições, mas como marcos, cujo sentido se precisa aos poucos, e que constituem uma espécie de repertório metafórico-vocabular próprio, um campo imaginário com delimitação particular no trabalho de Pina Bausch. Não é difícil perceber que tendem a respeitar um movimento de simbologia característico. Basta lembrar a cena da mulher bêbada com a ovelhinha negra no colo, no meio do rebanho de carneiros. Na seqüência se tem: a mulher caída no chão e a figura do 'anjo' aparecendo no mesmo lugar - uma bela síntese de vida, morte e ressurreição. $\mathrm{O}$ que importa não são as paisagens outonais ou de inverno do 'corpo' de Wuppertal. Não se especifica mais quem está no chão ou o porquê. Observa-se sim, movimentos, sombras que apontam símbolos, uma outra dimensão maior, mítica e universal

Neste grupo de imagens não deixa de ser curiosa, em certa medida, a inclusão do 'anjo'. Se, por um lado, em O Lamento da Imperatriz, a todo instante são sugeridas aproximações, no momento em que este impulso parece se intensificar - quando a mulher bêbada aparece no campo com a ovelha negra nos braços, em meio a um rebanho de ovelhas brancas - Bausch quebra a seqüência lógica da narrativa com a aparição do homem-anjo. Sua aproximação determina uma nova demarcação de distâncias, de tempo-espaço: o anjo inaugura a dimensão mítica desta cena, para onde convergem agora como ícones, os animais, a colina verde, a paz, o renascer.

Atração e afastamento também marcam a perspectiva simbólica da busca da 'mãe'. É como um dos termos de relação de analogia que se apresenta, a princípio, a figuração da 'mãe' no filme. Com a impressão de distanciamento, Bausch vai estruturando essa sensação da presença desejada e inexistente. É a menina que corre pelo bosque gritando, são as crianças 
carregadas pelos homens que também chamam pela mãe, é a mulher que corre, desesperada pelo bosque e estrada gritando por ela, enfim, é um texto composto como jogo poéticocromático de simetrias, de tensões que têm como objetivo a 'mãe'.

Na verdade não é bem da 'mãe' que trata o filme, mas de sua ausência. De uma figura que é figuração composta por um leque de referências simbólicas. O que importa é o silêncio, a sua não presença. São inúteis os gritos. A procura sintetiza-se no 'repouso', no corpo da mulher na neve, nele tudo descansa. De um lado, os gritos, o intenso movimento da busca; de outro, a figuração da mulher caída, estática, semicoberta pela neve. Movimento e paralisação, vida e morte.

Volta-se ao início, parecem dizer algumas cenas, mas na verdade narra-se o esforço de "transfiguração" no filme. Trata-se de uma certa essência da dimensão materna, única, ao mesmo tempo imagem e abstração.

Já no poema dito pela atriz, parece crescer a aproximação dessa reflexão sobre perda e solidão. Exibe-se pequenos fragmentos que compõem o lamento da perda de um amor: Eu disse: eras minha vida. / Ela disse: meu fim está chegando. / Eu disse: vem, vem lua, consola-me. Acrescenta-se quase de imediato em meio a essas aproximações, o silêncio, pois o que persiste é sempre a ausência da presença desejada. Tensão entre silêncio e som, entre equilíbrio e desequilíbrio, está em toda a obra de Bausch, aliás, é tema reiterado incessantemente por ela. É como se a sensação, a certeza de um sentido sempre em fuga, ao mesmo tempo impelisse e travasse figurações. O que, no caso de O Lamento da Imperatriz, no entanto, não deixa de ter uma bela contrapartida.

Porque se a busca pela 'mãe' enquanto figura mítica, simbólica, tende a ver seus contornos dissolvidos no silêncio, no espaço-tempo fílmico alguma coisa da dimensão maternal enforma, discretamente, quase sem que se perceba, a estruturação das cenas, assumindo a parte lírica do texto. O que aproxima são as diversas maneiras de buscar o carinho, o abrigo, o amor. Bausch vai compondo esse universo com cenas breves, muitas vezes enigmáticas, onde a figuração da mãe surge em alguns momentos, inesperada, quase uma ausência, mas o mais importante é que a mãe funciona então como "imago" da mãe mítica maior, Gaia, a terra, a cidade de Wuppertal ou qualquer outra, pois o sentido é universal.

De uma encenação fragmentária, metafórica, onde se pode gritar ou silenciar, Bausch acaba por marcar a escrita poética que opera. Assim, um filme-poema como $O$ Lamento da Imperatriz, permite tanto uma leitura vertical, interna a cada cena, quanto outra, mais regular, linear, que configura ligações bem diversas, um vaivém realizado em meio à cidade de Wuppertal, que funciona como eixo espaço-temporal para as várias cenas distribuídas ao longo do texto. A quantidade de dimensões, poemas-fragmentos, que se sucedem no trabalho de Bausch, é resultado de um hábil uso da movimentação corporal. Aos poucos, abre-se um leque que tematiza, sem alarde, o modo como se trama a procura da felicidade em uma forma lacerada de expressão. Trama poético-corporal que acontece quase no silêncio, na imprevisibilidade seca de cada cena- fragmento. 


\section{A cidade personagem}

Em O Lamento da Imperatriz, Pina Bausch deixa vir à tona (usando uma terminologia heideggeriana) um mundo que não é mundo, que se mostra e se oculta ao mesmo tempo. Esse 'deixar vir à tona' implica uma tarefa das mais exaustivas, pois a escrita de Bausch borra uma série de conexões que estabelecemos ao raciocinar, às quais estamos já muito acostumados no nível da nossa consciência ordinária.

Através de uma escrita corporal os personagens são traçados e constituídos, de uma forma em que sujeito e objeto não estão mecanicamente separados, mas constituem-se de forma recíproca. Por exemplo: as cenas no meio da cidade, ou as buscas incessantes de vários personagens, têm um cenário 'real' como fundo, mas é uma 'realidade' que precisa dos sujeitos-personagens para ter forma. Assim, a cidade vai tomando a forma que o olhar da câmara revela.

Há também uma superposição entre o cenário maior onde se passa a narrativa, a cidade de Wuppertal, e os elementos que a compõem: bosque, colina, estradas, o centro urbano, o edifício sede da companhia, o teleférico, a estufa, diversos cômodos de uma casa. Esse tipo de superposição ocorre igualmente entre o tempo e o espaço. $\mathrm{O}$ tempo, determinado pelas mudanças na natureza em diferentes estações, é possível de ser detectado nas tomadas externas, mas, às vezes, é questionável nas tomadas em ambientes fechados: indeterminado e/ou ilimitado explodindo os limites do espaço. Nesse sentido, se observa, por exemplo, a cena que tem uma piscina como fundo. Nesta cena, em determinado momento, fica-se sem saber se a mulher está andando da beira da piscina ou dentro de uma sala de onde, através de uma janela, se vê a piscina.

O próprio personagem principal da narrativa constitui a si mesmo como um objeto: o olho da câmara, num despojamento severo, em que parece haver inclusive uma indistinção, ao menos relativa, entre vida e não-vida, orgânico e inorgânico, como se sua existência primordial pudesse se dar, em alguns momentos, na ante-sala do viver, como a mãe, a Imperatriz, que não aparece.

O que seria esse personagem, que é vivo, mas que é também, antes de ser vivo, é sintagma que traz em si toda uma carga de significados ancestrais? É algo realmente, ou seria um feixe de possibilidades, como: os gritos, a mulher caída na neve, a mulher com as crianças no colo, a que dança na chuva, a mulher bêbada ou a velha senhora que dança no final?

A Imperatriz significa um amálgama de todas as personagens: a incerteza, a movimentação sempre para diante ou estática, o desespero, a busca de um caminho, um pedido, uma súplica, a repetição do corpo no mundo, como se o indivíduo não pudesse ser figurado senão por vários, numa ironia radical do sentido. Equilibrando-se para não desmoronar, avançando com insolência.

Pode-se ainda considerar a cidade de Wuppertal, também como um personagem que se manifesta concretamente, como uma força viva que pressiona com o trânsito urbano, desumanizando o homem, indiferente ao que acontece ao seu redor. Ou como cidadenatureza, com chão irregular, tempestades de neve e temporais, que desafia e está em combate com os personagens. 
Cenário que aponta a impossibilidade de ultrapassar essa resistência nascida da terra, de seus elementos naturais. Nesse sentido, a cidade é uma fortaleza inconquistável! Onde as coisas acontecem num círculo vital incontrolável, em que não se sabe se a cidade foi feita para as pessoas ou as pessoas para a cidade.

Lá está a cidade, onde coisas orgânicas e inorgânicas, vivas, vigiam: árvores, folhas caídas, neve, sombras. Todos são elementos, são sujeitos desse lamento, mas não falam. Calam-se. O silêncio é rompido pelo barulho dos corpos, o que torna enigmático o enquadramento simbólico de toda expressão corporal. Têm uma pulsão intrínseca, pois tudo o que é criado desencadeia associações, conexões ou rupturas.

Até mesmo as palavras, ditas pela atriz bailarina, provocadas na sua materialidade, independente do significado que possuem, ganham vida e podem de repente saltar para fora do filme. As palavras soam e remetem a lembranças, sonhos de sonhos.

Os personagens guardam uns dos outros sempre uma certa opacidade, não sendo nunca inteiramente compatíveis nas suas atitudes e ações. São recíprocos numa mútua indiferença: enquanto a mulher coelhinha anda perdida no terreno acinzentado, dois senhores caminham pelo mesmo lugar com determinação espacial que contrasta com a da mulher. Em outro momento, o mesmo lugar do bosque, uma espécie de avenida de árvores, por onde passa uma fila de homens que levam as crianças pela mão, logo depois reaparece como um estranho caminho de árvores numeradas por onde se move, meio perdida, uma mulher que segura uma garrafa.

Às vezes, o espaço natural está lado a lado como coisa e com coisas, o que redimensiona os objetos e a própria paisagem, apontando novas conexões ou deslocamentos. Este é o caso do elemento água, que perpassa todo o filme com várias conotações semânticas, que se encontram no seu valor amplo e mítico de purificação, força regeneradora, fertilizadora.

Na comunicação artística de Bausch, há algo bruto, brusco, imprevisível. A aproximação entre elementos dá-se pelas vias do constrangimento. A afetividade está enredada com o constrangimento. Por exemplo: as tentativas de carinho do rapaz com a mulher de rosto maquilado, o casal na cama, com amplas saias de tule, onde a cada investida do homem a mulher se retrai e arruma as saias, como se ter as saias intactas fosse objetivo primordial. Entre o objeto e a afetividade, vence o objeto, toda atitude amorosa é sempre alijada.

A afetividade é algo que aponta para o insubstituível de cada coisa, como a morte, exigindo, por vezes, como é o caso do amor, uma entrega completa, que perde o sujeito. Pina Bausch fala de amor, mas encontra simplesmente o sinal de fatalidade, esse insubstituível que mal se adivinha nas coisas, o insubstituível da morte. Como o gesto, o amor é reduzido até encontrar o irremediável. Com o amor se encontra o mundo, que tanto se procura, mas o que se observa são personagens perdidas. Nesse sentido, o amor é uma ameaça. Essa ameaça só não se torna efetiva, porque os caminhos que levam ao amor conduzem o homem de volta às coisas na sua concretude. Mesmo conduzindo de volta às coisas na sua concretude, o amor traz consigo a consciência de um perigo: a crueldade latente que seria a afronta da opacidade que separa os seres. 
Alguns personagens mantém-se para sempre afastados do amor, aferrando-se à sua própria opacidade. É o caso dos homens que levam as crianças, os dois velhos, o homem de terno preto. Não por acaso, quase sempre são personagens masculinos, corpos coberto, roupas escuras, que estabelecem a dimensão das sombras. Não há nestes personagens nem inocência, nem danação, nenhum deles se choca com a realidade, com o senso comum, talvez por serem a cruel realidade: homens calados, metidos em sobretudos ou ternos escuros. Assim também se estabelece o que vê de uma janela: a senhora curiosa que afasta com a mão a cortina e rapidamente a cerra, quando se percebe observada. Não passam disso, remetem aos edifícios sobre a chuva, impessoais e oniscientes, cegos na cidade cega. Mas existem os outros, os que buscam, mesmo que se percam, pois perder-se também é caminho.

A obra de Bausch parece ser, portanto, um olhar de lado e depois de outro lado, para cada coisa, sujeito, objeto, cidade. Cidade construída e perdida em vários combates, como as cidades erguidas e destruídas, renascidas dos próprios escombros. Coisas são vistas em sua intensidade e, à medida que sua opacidade é preservada, a afetividade expõe-se - sem nunca chegar de fato - a um atravessamento, que implicaria em sua própria aniquilação.

Bausch não é apenas a escritora que faz de sua escrita partitura, palavra, pintura, dança e coreografia. $\mathrm{O}$ que Bausch revela em foco primordial, é o jorro de uma energia que não se sabe nascida do corpo ou da cidade, que transforma a estética do movimento em pura intensidade. Escreve em signos que são mais um gesto que voz, sua escrita, errância do sentido, é o gesto corporal, força por excelência que desloca, absorve e reconecta sentidos. Como não pensar no apelo a um sentimento, na correspondência da marcha fúnebre que inicia o filme, quando a mulher atira em algo, com a repetição musical nas cenas finais, em que a atriz bêbada revela toda a solidão, a perda, a falta de horizonte. Lá está a "imperatriz", sozinha, bêbada, meio alucinada, feita de lembranças, de fragmentos, a figura em decadência de uma mulher. Mulher moldada em amor e dor, na busca eterna da felicidade.

Bausch propõe uma escrita situada em um terreno movediço necessário aos encontros, aos amores, uma escrita corporal concebida como ritmo e movimento, uma escrita que é carne e sensação.

O sentido é situado no eixo de uma economia dos afetos que embaralham os códigos do sujeito, da exaltação dos poderes do eu, desvelando-o como uma construção ficcional. A ênfase se desloca para a descoberta do tu, que é em Bausch pura escrita das sensações, do acontecimento. Uma vez evacuada a linearidade da história, a digestão é facilitada. O que era problema torna-se desafio. O que era voz abafada do sujeito torna-se voz solta em uníssono com a terra: à escuta da terra. Fala-se, então, de uma terceira pessoa do acontecimento. Mas, essa terceira pessoa, para além das regras, é rizoma, isto é, movimento, invenção sem criador nem dívida. Essa escrita da não-pessoa, de um "eu" articulador, desvela no âmbito da retórica bauschiana verdadeiras metáforas mágicas que servem, de certo modo, para otimizar o fora de si-mesmo, engendrando, para além do sujeito-narrador, um sopro que transforma a matéria corporal em corpo desejante, fecundador e não estéril.

O Lamento da Imperatriz cria através da violência de uma ausência, de um espaço vazio, linhas de fuga plenas que provocam o desvio de uma esperada linearidade narrativa, instaurando a dissolução. Um filme sem começo nem fim. Reticências, solturas, desembaraço: 
um filme-teatro-dança. Uma escrita para espectadores-leitores não preguiçosos, escrita que é uma convulsão da linguagem. Transmite não uma história, mas atos que vivem do corpo. As imagens geram o inconcluso, uma profunda desordem orgânica. Embora seu texto seja todo atravessado de ponta a ponta por um frágil fio condutor: o do mergulho na matéria corporal, o da paixão, da busca incansável do amor.

Conforme o desejo nietzschiano de uma osmose entre a palavra e o gesto, percebe-se, em Bausch, o passo dançado como uma metáfora poética. O novo texto-dança-teatro-filme é texto-traço, traço como corpo da escrita, traço como pele. Uma escrita rizomática que não cheira à imitação, mas à vida enquanto plenitude desumana. Uma escrita órfã de significações e de significados, mas plena de sentido, que renuncia a ter apenas um significado, um único momento de ser ato. Assim, Bausch parte para o cinema, onde o momento pode ser repetido através da fita magnética.

Arte de deslocamento, atalho, desvio, uma geografia do corpo em movimento, as imagens bauschianas, corpos e percursos, são uma topologia em atividade. Criando e desviando imagens, Bausch outorga a seu texto-movimento o eterno deslocamento dos personagens, exigindo que eles se reencontrem e também se deixem. Na viagem provocação, ao desviar ou romper com qualquer suposta narrativa linear das imagens, a autora provoca a síncope, o movimento oblíquo. Com isso torna disponíveis todas as visões, todas as interpretações, todos os sentidos possíveis. Desvia o sentido para o "infinito" isto é, para a embriaguez polifônica de todos os possíveis.

Com efeito, coreografar é desmesurar, despintar, desmarcar o espaço; escrever com o corpo organizar formas. Dançar é praticar fisicamente a multiplicidade dos possíveis em seu deciframento cacofônico. Coreografar é dançar, é prospectar o universo! A escrita bauschiana não conhece a permanência, ela desaparece no próprio espaço-texto, espaço-cena, espaçotempo, mas permanece, é futuro, na nossa memória.

O Lamento trata do modo como se pode perpetuar o que já não existe, ou melhor, sobre o que fazer com as imagens e vozes perdidas que persistem como fantasmas nos vazios da memória. A narração implica memória, pois se lembrar é contar a si mesmo uma história, ainda que em fragmentos, em estilhaços dispersos. Wuppertal apresentada por Bausch é um modelo em miniatura das grandes metrópoles transnacionais, onde todas as línguas se misturam, onde a corporeidade é a linguagem comum.

O espaço da cidade é espaço fronteiriço de reinscrição subjetiva, de contradições, onde coexistem diferenças, mas onde também se tem a sensação de que todos sonham o mesmo sonho, ainda que em realidades diferentes.

É assim que a última cena invade o cotidiano, mistura realidade, ficção e mito, congelase em um monólogo sem fim, posto que foi concebida para ser eterna. E até na eternidade da foto o encontro entre a realidade e a ficção é perceptível, pois enquanto a velha senhora baila, sai dos sonhos e acorda o espectador em outra realidade. 


\section{Notas}

${ }^{1}$ BAUSCH, Pina. O Lamento da Imperatriz (Die Klage der Kaiserin). Direção e Coreografia: Pina Bausch. Editor: Nina von Kreisler, Michael Felber, Martin Zevort. Produção: L' Arche Éditeur. Versão em vídeo - VHS. Cor.103' 1989.

2 WENDERS, Wim. "Le Souffle de l'Ange”. In Cahiers du Cinéma. Paris: 1988 (tradução da autora).

3 Ibidem, p.25.

${ }^{4}$ POULET, Georges. Etudes sur le temps humain/4. Collection Agora. Paris:Éditeur Presses Pocket. 1990.p.59 (tradução da autora).

${ }^{5}$ Ibidem; p. 59

\section{Bibliografia}

FERNANDES, Ciane. Pina Bausch e o Wuppertal Dança-Teatro. Repetição e Transformação. Ed. Hucitec. São Paulo, 2000.

POULET, Georges. Etudes sur le temps humain/4. Collection Agora. Paris:Éditeur Presses Pocket. 1990.

NICLAS, Lorrina. Danse - Corps provisoire. Paris: Armand Colin, 1992, p. 46-52.

VIGÉE, Claude. La faille du regard. Paris: Flammarion, 1987.

VIGÉE, Claude. L'Extase et L'Errance. Paris, Grasset 1982.

WENDERS, Wim. "Le Souffle de l'Ange”. In Cahiers du Cinéma. Paris: 1988.p.25-37.

\section{Videografia}

BAUSCH, Pina. O Lamento da Imperatriz (Die Klage der Kaiserin). Direção e Coreografia: Pina Bausch. Editor: Nina von Kreisler, Michael Felber, Martin Zevort. Produção: L' Arche Éditeur. Versão em vídeo - VHS. Cor.103' 1989. 